\title{
ESTOQUE DE CARBONO EM ÁREAS DE RESTAURAÇÃO FLORESTAL DA MATA ATLÂNTICA
}

\author{
Aline Damasceno de Azevedo ${ }^{1}$, Marcio Rocha Francelino ${ }^{2}$, Rodrigo Camara ${ }^{1}$, Marcos Gervasio Pereira ${ }^{1^{*}}$, \\ Paulo Sérgio dos Santos Leles ${ }^{1}$ \\ ${ }^{1}$ Universidade Federal Rural do Rio de Janeiro, Seropédica, Rio de Janeiro, Brasil - alinerural.rj@ gmail.com; rcamara73@gmail.com; \\ marcio.francelino@gmail.com; gervasio@ufrrj.br; pleles@ufrrj.br \\ ${ }^{2}$ Universidade Federal de Viçosa, Viçosa, Rio de Janeiro, Brasil - marcio.francelino@gmail.com
}

Recebido para publicação 09/08/2017 - Aceito para publicação: 08/02/2018

\begin{abstract}
Resumo
Ecossistemas florestais são importantes no processo de estocagem de carbono da atmosfera. Áreas de reflorestamentos podem contribuir de maneira substancial nesse processo e diminuir a pressão extrativista sobre florestas nativas. Este trabalho objetivou avaliar a biomassa acima do solo viva (por meio do método nãodestrutivo - equações alométricas) e morta (serapilheira) e o estoque de carbono nesses compartimentos em áreas de reflorestamento com diferentes idades (3, 5 e 7 anos) e em área de Floresta Ombrófila Densa (testemunha), localizadas no município de Cachoeiras de Macacu (RJ). Foram alocadas 30 parcelas (10 x $10 \mathrm{~m}$ cada) na área testemunha e 20 parcelas $(20$ × 30 m cada) nas áreas de reflorestamento. Os indivíduos arbóreos foram identificados, e a altura total, circunferência e diâmetro à altura do peito foram medidos. A serapilheira foi coletada com gabarito quadrado ( 1 x $1 \mathrm{~m}$ ) em cinco repetições em cada área. Os valores de biomassa acima do solo e carbono estocado aumentaram à medida que a idade dos plantios de restauração florestal avançou. Os modelos alométricos utilizados foram adequados no estudo. Contudo, é necessário testar a confiabilidade dos dados com a utilização do método destrutivo nas áreas reflorestadas.

Palavras-chave: Sequestro de carbono, restauração florestal, biomassa acima do solo, serapilheira.
\end{abstract}

\begin{abstract}
Carbon stock in forest restoration areas of the Atlantic Forest. Forest ecosystems are important in the process of storing carbon from the atmosphere. Reforestation areas can contribute substantially in this process and reduce the extractive pressure over native forests. This study aimed to assess the aboveground live biomass (by non-destructive method - allometric equations) and dead biomass (litter layer standing stock) and carbon stock in these compartments at areas of reforestation of different ages (3, 5, and 7 years old) and at a Dense Ombrophylous Forest (control) area, located in the municipality of Cachoeiras de Macacu (state of Rio de Janeiro, Brazil). We allocated 30 plots $(10 \times 10 \mathrm{~m}$ each) in the control area and 20 plots $(20 \times 30 \mathrm{~m}$ each) in the reforestation areas. Tree individuals were identified, and total height, circumference, and diameter at breast height were measured. The litter standing stock was collected by square gauge $(1 \mathrm{x} 1 \mathrm{~m})$ in five replicates at each area. The values of aboveground biomass and stored carbon increased as the age of forest restoration plantings advanced. The allometric models used were adequate in the study. However, it is necessary to test the reliability of the data, using the destructive method in the reforested areas.

Keywords: Carbon sequestration, forest restoration, aboveground biomass, litter.
\end{abstract}

\section{INTRODUÇÃO}

O processo de fotossíntese permite que os ecossistemas florestais atuem como sumidouro do carbono atmosférico. Sendo assim, o desflorestamento pode ser considerado uma das principais causas do aumento das concentrações de gás carbônico na atmosfera, refletido no incremento de aproximadamente $2{ }^{\circ} \mathrm{C}$ na temperatura do ar na América do Sul entre os anos de 2010 e 2040 (REBOITA et al., 2014). Como resultado, a atividade dos organismos decompositores é acelerada e, portanto, o carbono estocado sob a forma de matéria orgânica no solo é liberado para a atmosfera, o que potencializa o aquecimento global (HOPKINS et al., 2012). Esse panorama demonstra a necessidade de se restaurarem áreas desflorestadas, com a finalidade de aumentar o sequestro e estoque de carbono. A restauração de áreas desflorestadas também contribui para a conservação da biodiversidade, fato de relevante importância no âmbito da Mata Atlântica devido aos elevados níveis de diversidade de espécies, endemismo, número de espécies ameaçadas de extinção e redução de sua área original (JOLY et al., 2014).

Diversos fatores, como condições de clima e solo, além de idade e composição de espécies, podem influenciar na capacidade de estoque de carbono na biomassa aérea e radicular de ecossistemas florestais (BROWN; LUGO, 1990). Dessa maneira, estudos dedicados ao levantamento da estrutura e estoque de carbono

FLORESTA, Curitiba, PR, v. 48, n. 2, p. 183-194, abr/jun. 2018.

Azevedo. A. D. et.al.

ISSN eletrônico 1982-4688

DOI: $10.5380 /$ rf.v48 i 2.54447 
nesses ecossistemas têm papel de destaque no cerne das questões ambientais atuais, que envolvem o ciclo do carbono. Estes podem ser realizados por meio do emprego de modelos matemáticos nos quais são utilizadas variáveis levantadas em inventário florestal, como diâmetro do tronco à altura do peito (1,3 m acima do solo) e/ou altura das árvores (TIEPOLO et al., 2002; VIEIRA et al., 2011). Além do compartimento vivo, o compartimento morto pode também ser considerado, com a mensuração da massa de matéria seca da camada de serapilheira disposta sobre a superfície do solo florestal (TIEPOLO et al., 2002; VIEIRA et al., 2011). Contudo, esses dados ainda são incipientes no Brasil, o que indica que estudos dessa natureza podem contribuir como estímulo à preservação de áreas não impactadas por atividades antrópicas e à recuperação de áreas já desflorestadas.

No presente estudo, testou-se a hipótese de que áreas reflorestadas com espécies nativas são capazes de contribuir para o estoque de carbono na biomassa aérea, com incremento proporcional à idade dos reflorestamentos em áreas de Floresta Ombrófila Densa. Assim, objetivou-se estimar o estoque de carbono na massa vegetal viva acima do solo, pelo método não-destrutivo, e na camada de serapilheira em áreas de restauração da Mata Atlântica com diferentes idades no município de Cachoeiras de Macacu (RJ).

\section{MATERIAL E MÉTODOS}

A Reserva Ecológica de Guapiaçu (REGUA) foi criada em 1996 e se tornou uma Unidade de Conservação do tipo Reserva Particular do Patrimônio Natural (RPPN) no ano de 2012. Atualmente, possui 6.431 ha de terras de propriedades particulares e 4.208 ha de terras de propriedades parceiras, que perfazem 10.639 ha de áreas protegidas pela REGUA. Essa reserva está inserida no município de Cachoeiras de Macacu, no estado do Rio de Janeiro, e localizada entre as coordenadas $22^{\circ} 27^{\prime} 10^{\prime \prime}$ de latitude sul e $42^{\circ} 46^{\prime} 13^{\prime \prime}$ de longitude oeste, com altitudes que variam entre 40 e 2.200 metros acima do nível médio do mar (Figura 1).

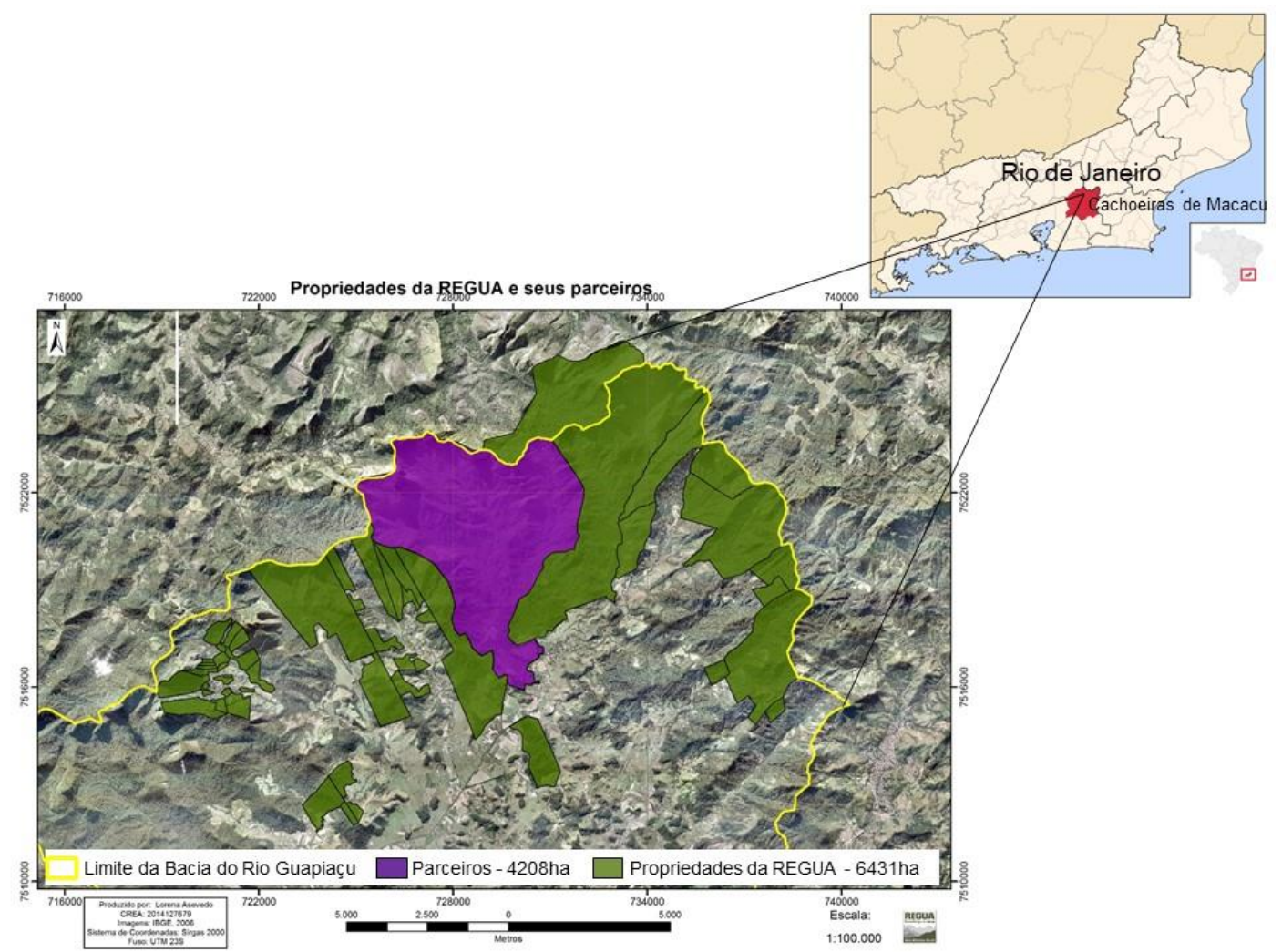

Figura 1. Localização da Reserva Ecológica do Guapiaçu (REGUA) no município de Cachoeiras de Macacu, Rio de Janeiro, Brasil (mapa da área elaborado por Lorena Asevedo, 2017).

Figure 1. Location of the Guapiaçu Ecological Reserve (REGUA) in the municipality of Cachoeiras de Macacu, state of Rio de Janeiro, Brazil (area map made by Lorena Asevedo, 2017).

O clima da região, pela classificação de Köppen, foi identificado como do tipo Af, ou seja, tropical com verão chuvoso e inverno seco, sem uma estação marcadamente seca. A precipitação média mensal varia de $337,8 \mathrm{~mm}$ (fevereiro) a 59,3 $\mathrm{mm}$ (julho), com total anual de $2.050 \mathrm{~mm}$. A temperatura média anual é de $21,9^{\circ} \mathrm{C}$, 
sendo janeiro o mês mais quente $\left(25,3^{\circ} \mathrm{C}\right)$, e julho, o mês mais frio $\left(17,9^{\circ} \mathrm{C}\right)$. Na região, a topografia varia em todas as formas de relevo, desde o plano até o escarpado, com presença de afloramentos rochosos. As classes de solo predominantes na região são: Latossolo Vermelho-Amarelo nas colinas e morrotes; Cambissolo Háplico e Neossolo Litólico nas áreas escarpadas e de afloramentos rochosos, respectivamente; Argissolo Amarelo e Vermelho-Amarelo e Planossolo Háplico, que podem ser encontrados nos maciços alcalinos; e Neossolo Flúvico e Gleissolo nas áreas hidromórficas (PINHEIRO et al., 2014).

A cobertura vegetal original foi classificada como Floresta Ombrófila Densa, variando em três diferentes fitofisionomias: Floresta Ombrófila Densa Aluvial nas partes mais baixas da paisagem, em relevo plano; Floresta Ombrófila Densa das Terras Baixas nas áreas de planície costeira, em relevo suave ondulado; Floresta Ombrófila Densa Submontana, em relevo ondulado, e Montana na parte mais alta da porção da paisagem, onde o relevo se apresenta montanhoso e escarpado. No entorno da REGUA, ocorrem fragmentos florestais secundários de diferentes tamanhos, imersos em uma matriz onde predominam áreas de pastagem e agricultura.

Para o estudo, foram selecionadas três áreas de restauração florestal com idades de 3 (REF3), 5 (REF5) e 7 anos (REF7), dispostas em relevo suave ondulado, ondulado e plano, respectivamente. Os plantios foram realizados nos anos de 2004, 2006 e 2008 em aproximadamente 9,6 ha, 2,5 ha e 3,4 ha, respectivamente. Segundo o responsável pela propriedade, antes do plantio, o solo foi preparado com aragem, gradagem e subsolagem. A disposição das mudas no campo não obedeceu a alinhamento ou espaçamento definidos, o que resultou em diferentes densidades populacionais.

$\mathrm{Na}$ maior parte dos reflorestamentos, foram empregadas mudas produzidas com o material genético dos remanescentes florestais da própria reserva, entre espécies nativas pioneiras, principalmente, secundárias iniciais, secundárias tardias e clímax. Para a realização do inventário florestal, foram instaladas parcelas (unidades amostrais de 20 m x 30 m), sendo 10 no REF3, quatro no REF5 e seis no REF7, totalizando 6.000, 2.400 e $3.600 \mathrm{~m}^{2}$ amostrados, respectivamente. Como testemunha, considerou-se um fragmento de floresta preservada (MATA) de aproximadamente 1.700 hectares, disposto nos limites da REGUA, onde o inventário foi realizado em 30 parcelas de $10 \times 10 \mathrm{~m}\left(3.000 \mathrm{~m}^{2}\right)$. A partir da curva do coletor gerada, foi possível observar que não houve suficiência amostral para uma representação mais ampla da riqueza de espécies na área estudada, ou seja, é necessário aumentar o esforço amostral.

Todas as parcelas tiveram suas coordenadas registradas por receptor GPS. Mediu-se a circunferência à altura do peito (CAP), com o auxílio de fita centimetrada, de todos os indivíduos arbóreos nos reflorestamentos. Posteriormente, os valores de CAP foram convertidos para diâmetro à altura do peito (DAP). Na MATA, consideraram-se apenas os indivíduos arbóreos com CAP $\geq 10 \mathrm{~cm}$, e foram, ainda, desconsiderados os indivíduos com DAP $<4 \mathrm{~cm}$, por representarem especificamente o sub-bosque de uma floresta madura. A vegetação do subbosque em floresta tropical úmida pode alcançar valores menores que $3 \%$ da biomassa acima do solo. Somado aos baixos níveis de luz incidente no solo, torna-se desprezável a contribuição desse estrato para o incremento de biomassa total (CLARK et al., 2001). Todos os indivíduos registrados foram identificados em nível de família, gênero e espécie, e sua altura total $(\mathrm{Ht})$ foi estimada visualmente.

A biomassa viva acima do solo de cada indivíduo arbóreo (em $\mathrm{kg}$ ) foi estimada nas unidades amostrais pelo método não-destrutivo e, depois, convertida a $\mathrm{Mg} \mathrm{ha}^{-1}$. Nos reflorestamentos, empregou-se a equação alométrica proposta por Brown (1997), ajustada para áreas de restauração em florestas tropicais: Biomassa = exp $(-2,134+2,53 * \ln$ DAP). Na MATA, considerou-se a equação alométrica de Brown (1997), analisada e ajustada por Tiepolo et al. (2002), que propuseram um novo modelo para a Mata Atlântica, especificamente para áreas sob domínio de Floresta Ombrófila Densa, a partir de amostragens destrutivas: Biomassa = 21,297 - $(6,953 *$ DAP $)+$ $\left(0,74 *\left(\mathrm{DAP}^{2}\right)\right)$.

Devido à abundância de palmeiras (plantas da família Arecaceae) na MATA, representadas principalmente pela espécie climáxica Euterpe edulis Mart. (segunda espécie mais abundante, 25 ind ha ${ }^{-1}$ ), pela secundária tardia Astrocaryum aculeatissimum (Schott) Burret (sétima espécie mais abundante, 15 ind ha-1), que são endêmicas do bioma Mata Atlântica, além da Geonoma sp. ( 3 ind ha ${ }^{-1}$ ), suas biomassas vivas aéreas foram analisadas separadamente e, posteriormente, somadas à biomassa total por meio da equação proposta por Tiepolo et al. (2002), que deve ser aplicada especificamente para indivíduos pertencentes à família Arecaceae: Biomassa $=(0,3999+(7,907 * \mathrm{Ht}))$.

Os teores de carbono na biomassa verde ou fresca variam conforme a espécie florestal (WATZLAWICK et al., 2014) e raramente ultrapassam 50\% (DALLAGNOL et al., 2011). Por não ter sido possível obter a real porcentagem de carbono contido na biomassa das espécies nas áreas estudadas, consideramos, de maneira genérica, que o teor desse elemento na biomassa das plantas foi igual a aproximadamente $50 \%$ da matéria de massa seca (TIEPOLO et al., 2002). Dessa maneira, o estoque de carbono ( $\left.\mathrm{Mg} \mathrm{C} \mathrm{ha}^{-1}\right)$ foi estimado por meio da divisão da biomassa $\left(\mathrm{Mg} \mathrm{ha}^{-1}\right)$ por dois, assumindo-se que se pode obter valores superestimados.

FLORESTA, Curitiba, PR, v. 48, n. 2, p. 183-194, abr/jun. 2018.

Azevedo. A. D. et.al.

ISSN eletrônico 1982-4688

DOI: $10.5380 /$ rf.v48 i 2.54447 
A biomassa morta acima do solo também foi avaliada, por meio de coleta da camada de serapilheira disposta sobre a superfície do solo e circunscrita em um gabarito quadrado de madeira com as dimensões de 1 x $1 \mathrm{~m}\left(1 \mathrm{~m}^{2}\right)$. Para tanto, cinco amostras simples foram obtidas em cada reflorestamento e na mata nativa nas parcelas delimitadas em março de 2011. Essas amostras foram embaladas e secas em estufa de circulação forçada de ar a $65^{\circ} \mathrm{C}$ por $48 \mathrm{~h}$ (ALONSO et al., 2015). Em seguida, o material foi pesado (g) e estratificado em: folhas, galhos, material reprodutivo (flor, fruto e semente), braquiária (Brachiaria decumbens), e outros (refugo, raízes, coprólitos, etc), para o cálculo de seu percentual em cada área amostral (a partir da média entre cinco repetições). $\mathrm{O}$ total de cada área foi expresso em $\mathrm{Mg} \mathrm{ha}^{-1}$. O estoque de carbono presente nesse compartimento foi calculado da mesma forma que o considerado para a biomassa viva acima do solo. A importância de se estimar a biomassa da camada de serapilheira reside no fato de que esse compartimento pode representar até $5 \%$ do carbono acima do solo, tanto em florestas tropicais como em subtropicais (BALBINOT et al., 2017).

A análise multivariada de agrupamento hierárquico foi realizada considerando-se os valores totais da biomassa viva aérea, camada de serapilheira e estoque de carbono nos respectivos compartimentos com o objetivo de identificar possíveis similaridades entre as áreas estudadas (REF3, REF5, REF7 e MATA). Nesse procedimento, empregou-se o método da distância de ligação simples de Bray-Curtis, com auxílio do programa PAST versão $2.17 \mathrm{c}$.

\section{RESULTADOS}

Com o aumento da idade dos reflorestamentos, verificou-se aumento gradual da biomassa aérea total, tanto da parte aérea viva quanto da camada de serapilheira disposta sobre a superfície do solo, assim como do estoque de carbono nesses dois compartimentos (Tabela 1). As áreas REF3, REF5 e REF7 corresponderam a aproximadamente $15,7 \%, 18,6 \%$ e $27,6 \%$ da biomassa aérea total observada na MATA, respectivamente.

Tabela 1. Quantificação total de biomassa aérea viva (BA), biomassa da camada de serapilheira (CS), estoque de carbono na biomassa viva aérea (CBA) e na camada de serapilheira (CCS) em reflorestamentos com 3 (REF3), 5 (REF5) e 7 anos (REF7) e em área de mata nativa (MATA) na Reserva Ecológica de Guapiaçu, Rio de Janeiro, Brasil.

Table 1. Total quantification of aboveground live biomass (BA), litter layer standing stock biomass (CS), carbon stock in aboveground live biomass (CBA) and in litter layer standing stock (CCS) in reforestations of 3 (REF3), 5 (REF5), and 7 years old (REF7), and in a native forest area (MATA) in the Guapiaçu Ecological Reserve, state of Rio de Janeiro, Brazil.

\begin{tabular}{|c|c|c|c|c|c|c|}
\hline \multirow[t]{2}{*}{ Local } & BA & CS & Total & CBA & CCS & Total \\
\hline & \multicolumn{6}{|c|}{ 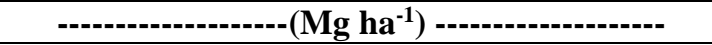 } \\
\hline REF3 & 39,88 & 3,82 & 43,70 & 19,94 & 1,91 & 21,85 \\
\hline REF5 & 45,78 & 5,79 & 51,57 & 22,89 & 2,89 & 25,78 \\
\hline REF7 & 71,24 & 5,33 & 76,57 & 35,62 & 2,67 & 38,29 \\
\hline MATA* & 273,35 & 4,53 & 277,88 & 136,68 & 2,26 & 138,94 \\
\hline
\end{tabular}

*incluindo palmeiras.

Com relação ao estoque de carbono na camada de serapilheira nos plantios, o valor dessa variável mudou conforme sua idade e representou, aproximadamente, $13 \%, 16 \%$ e $11 \%$ do total observado para a biomassa acima do solo em REF3, REF5 e REF7, respectivamente. Já na MATA, o percentual encontrado foi de 2\%. Os valores de estoque de carbono na camada de serapilheira para as áreas REF5 e REF7 foram mais próximos entre si, em comparação com o plantio REF3 (Tabela 1).

Entre as dez espécies arbóreas identificadas mais representativas na biomassa aérea viva nos reflorestamentos, a maioria pertencia à família botânica Fabaceae $(67 \%, 53 \%$ e 49\% em REF3, REF5 e REF7, respectivamente) e ao grupo ecológico das pioneiras (83\%, 59\% e 65\% em REF3, REF5 e REF7, respectivamente) (Tabela 2). Estas contribuíram com mais de $82 \%$ da biomassa total. A espécie pioneira Guarea guidonia foi a mais representativa na biomassa aérea produzida na MATA.

Tabela 2. Valores de área basal (AB), biomassa aérea viva (BA), estoque de carbono na biomassa viva aérea (CBA), contribuição relativa na biomassa aérea viva (CR) e grupo ecológico (GE) das 10 espécies mais representativas em reflorestamentos com 3 (REF3), 5 (REF5) e 7 anos (REF7) e em área de mata nativa (MATA) na Reserva Ecológica de Guapiaçu, Rio de Janeiro, Brasil. 
Table 2. Basal area (AB), aboveground live biomass (BA), carbon stock in aboveground live biomass (CBA), relative contribution in aboveground live biomass (CR), and ecological group (GE) of the 10 most representative species in reforestations of 3 (REF3), 5 (REF5), and 7 years old (REF7), and in a native forest area (MATA) in the Guapiaçu Ecological Reserve, state of Rio de Janeiro, Brazil.

\begin{tabular}{|c|c|c|c|c|c|c|}
\hline Reflorestamento / Família & Espécie & $\mathbf{A B}$ & BA & CBA & CR & GE \\
\hline REF3 & & $\left(\mathrm{m}^{2}\right)$ & ----(M & g)---- & $\%$ & \\
\hline Bombacaceae & Ceiba speciosa (A. St.-Hil.) Ravenna & 0,05 & 0,39 & 0,19 & 1,63 & ST \\
\hline \multirow[t]{4}{*}{ Fabaceae } & Inga edulis Mart. & 0,13 & 0,74 & 0,37 & 3,08 & $\mathrm{P}$ \\
\hline & Piptadenia gonoacantha (Mart.) J.F. Macbr. & 1,50 & 10,09 & 5,05 & 42,17 & $\mathrm{P}$ \\
\hline & Piptadenia paniculata Benth. & 0,69 & 4,01 & 2,01 & 16,76 & $\mathrm{P}$ \\
\hline & Schizolobium parahyba (Vell.) S.F. Blake & 0,17 & 1,22 & 0,61 & 5,09 & $\mathrm{P}$ \\
\hline Lauraceae & Nectandra membranacea (Swartz) Griseb. & 0,23 & 1,05 & 0,52 & 4,37 & $\mathrm{P}$ \\
\hline Melastomataceae & Tibouchina granulosa (Desr.) Cogn. & 0,16 & 0,97 & 0,48 & 4,04 & $\mathrm{P}$ \\
\hline \multirow[t]{2}{*}{ Myrtaceae } & Syzygium jambolanum (Lam.) DC. & 0,11 & 0,57 & 0,9 & 2,39 & SI \\
\hline & Joannesia princeps Vell. & 0,07 & 0,51 & 0,26 & 2,13 & $\mathrm{P}$ \\
\hline \multirow[t]{2}{*}{ Verbenaceae } & Citharexylum myrianthum Cham. & 0,24 & 1,44 & 0,72 & 6,03 & $\mathrm{P}$ \\
\hline & Total & 3,34 & 20,98 & 10,49 & 87,69 & \\
\hline \multicolumn{7}{|l|}{ REF5 } \\
\hline Cannabaceae & Trema micrantha (L.) Blume & 0,06 & 0,36 & 0,18 & 3,30 & $\mathrm{P}$ \\
\hline \multirow[t]{5}{*}{ Fabaceae } & Centrolobium tomentosum Guillemin ex Benth. & 0,13 & 0,67 & 0,33 & 6,06 & $\mathrm{P}$ \\
\hline & Dalbergia nigra (Vell.) Allemao ex Benth. & 0,04 & 0,21 & 0,11 & 1,96 & $\mathrm{P}$ \\
\hline & Inga edulis Mart. & 0,13 & 0,96 & 0,48 & 8,71 & $\mathrm{P}$ \\
\hline & Piptadenia gonoacantha (Mart.) J.F. Macbr. & 0,37 & 2,56 & 1,28 & 23,33 & $\mathrm{P}$ \\
\hline & Plathymenia foliolosa Benth. & 0,19 & 1,70 & 0,85 & 15,46 & $\mathrm{C}$ \\
\hline Lecythidaceae & Cariniana legalis (Mart.) Kuntze & 0,03 & 0,16 & 0,08 & 1,45 & $\mathrm{C}$ \\
\hline Melastomataceae & Tibouchina granulosa (Desr.) Cogn. & 0,22 & 1,45 & 0,73 & 13,22 & $\mathrm{P}$ \\
\hline Myristicaceae & Virola bicuhyba (Schott) Warb. & 0,17 & 0,97 & 0,48 & 8,79 & ST \\
\hline \multirow[t]{2}{*}{ Polygonaceae } & Triplaris americana $\mathrm{L}$. & 0,03 & 0,22 & 0,11 & 1,99 & $\mathrm{P}$ \\
\hline & Total & 1,36 & 9,26 & 4,63 & 84,27 & \\
\hline \multicolumn{7}{|l|}{ REF7 } \\
\hline Annonaceae & Anonna mисоsa (Jacq.) Baill. & 0,09 & 0,42 & 0,21 & 2,66 & SI \\
\hline Caricaceae & Jacaratia spinosa (Aubl.) A. DC. & 0,13 & 0,77 & 0,38 & 5,68 & $\mathrm{P}$ \\
\hline \multirow[t]{4}{*}{ Fabaceae } & Centrolobium tomentosum Guillemin ex Benth. & 0,68 & 2,52 & 1,26 & 16,94 & $\mathrm{P}$ \\
\hline & Inga edulis Mart. & 0,49 & 2,81 & 1,41 & 17,57 & $\mathrm{P}$ \\
\hline & Leucaena leucocephala (Lam.) R. de Wit & 0,09 & 0,33 & 0,16 & 1,81 & $\mathrm{P}$ \\
\hline & Plathymenia foliolosa Benth. & 0,39 & 2,06 & 1,03 & 14,49 & $\mathrm{C}$ \\
\hline Meliaceae & Guarea guidonia (L.) Sleumer & 0,13 & 0,51 & 0,25 & 2,93 & $\mathrm{P}$ \\
\hline Moraceae & Morus nigra $\mathrm{L}$. & 0,37 & 1,31 & 0,65 & 8,12 & $\mathrm{P}$ \\
\hline Phytolaccaceae & Gallesia integrifolia (Spreng.) Harms & 0,28 & 1,42 & 0,71 & 8,46 & $\mathrm{P}$ \\
\hline \multirow[t]{2}{*}{ Rhamnaceae } & Hovenia dulcis Thunb. & 0,16 & 0,64 & 0,32 & 3,76 & $\mathrm{P}$ \\
\hline & Total & 2,83 & 12,77 & 6,39 & 82,43 & \\
\hline \multicolumn{7}{|l|}{ MATA } \\
\hline Apocynaceae & Geissospermum laevis Miers & 0,25 & 1,95 & 0,98 & 2,44 & ST \\
\hline Meliaceae & Cabralea canjerana (Vell.) Mart. & 0,33 & 2,36 & 1,18 & 2,95 & ST \\
\hline
\end{tabular}

FLORESTA, Curitiba, PR, v. 48, n. 2, p. 183-194, abr/jun. 2018.

Azevedo. A. D. et.al.

ISSN eletrônico 1982-4688 
Guarea guidonia (L.) Sleumer

Trichilia pallens C. DC.

Fabaceae

Sapotaceae

Lauraceae

Symplocaceae
Apuleia leiocarpa (Vogel) J.F. Macbr.

Cassia ferruginea (Schrad.) Schrad. ex DC.

Piptadenia gonoacantha (Mart.) J.F. Macbr.

Chrysophyllum sp

Nectandra membranacea (Swartz) Gris.

Symplocos $\mathrm{sp}$

Total

\begin{tabular}{ccccc}
2,48 & 17,74 & 8,87 & 22,16 & $\mathrm{P}$ \\
0,26 & 2,10 & 1,05 & 2,63 & $\mathrm{SI}$ \\
0,27 & 2,01 & 1,05 & 2,62 & $\mathrm{C}$ \\
0,69 & 5,14 & 2,57 & 6,43 & $\mathrm{P}$ \\
0,52 & 3,72 & 1,86 & 4,65 & $\mathrm{P}$ \\
0,61 & 4,67 & 2,34 & 5,84 & $\mathrm{NE}$ \\
0,67 & 4,55 & 2,28 & 5,69 & $\mathrm{P}$ \\
0,33 & 2,68 & 1,34 & 3,34 & $\mathrm{NE}$ \\
6,41 & 46,92 & 23,52 & 58,75 & \\
\hline
\end{tabular}

P: espécie pioneira; SI: Secundária inicial; ST: Secundária tardia; C: Clímax; NE: Não especificado.

A análise dos componentes da camada de serapilheira evidenciou que a contribuição de folhas foi maior em REF3 e REF7, seguido de galhos (Figura 2). Esse padrão se inverteu em REF5 e MATA, onde a contribuição de galhos foi maior, seguida de folhas. Houve incremento da contribuição do material reprodutivo na camada de serapilheira com o aumento da idade dos reflorestamentos. A contribuição percentual do material reprodutivo apresentou praticamente o mesmo valor em REF7 em relação à mata nativa. Nos reflorestamentos estudados, a contribuição da referida braquiária, que foi baixa na camada de serapilheira nos reflorestamentos (no máximo até $6 \%$ do total), diminuiu conforme a idade aumentou e não ocorreu na MATA.
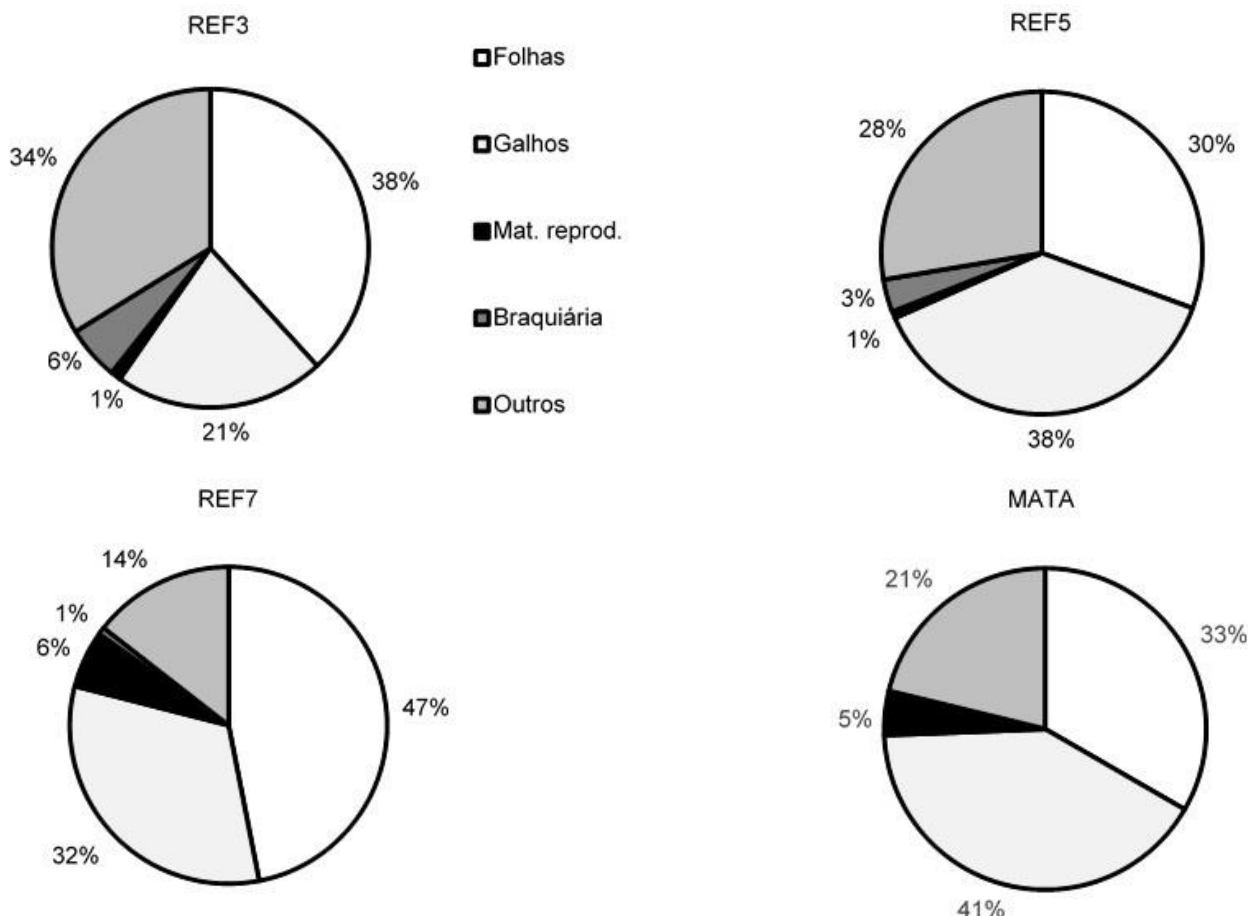

Figura 2. Contribuição percentual dos componentes da camada de serapilheira em reflorestamentos com 3 (REF3), 5 (REF5) e 7 anos (REF7) e em área de mata nativa (MATA) na Reserva Ecológica de Guapiaçu (REGUA), Rio de Janeiro, Brasil.

Figure 2. Percentage contribution of litter layer standing stock components in reforestations of 3 (REF3), 5 (REF5), and 7 years old (REF7), and in a native forest area (MATA) in the Guapiaçu Ecological Reserve (REGUA), state of Rio de Janeiro, Brazil.

O dendrograma de análise de agrupamento hierárquico indicou a formação de dois grandes grupos: um formado isoladamente pela MATA; e outro formado pela reunião dos reflorestamentos (Figura 3). Isso demonstrou a elevada dissimilaridade entre a mata nativa e os reflorestamentos. Dentro do grupo formado pelos reflorestamentos, observou-se a formação de subgrupos, formados por REF3 e REF5, cuja distância de ligação foi 
menor (aproximadamente 0,83) em comparação com a distância de ligação entre essas duas áreas e REF7 (aproximadamente 0,92).

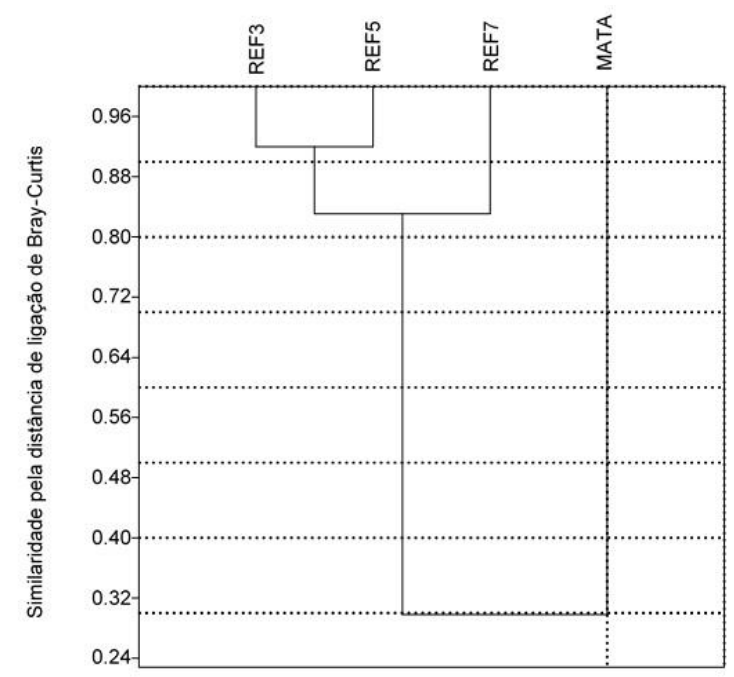

Figura 3. Dendrograma de análise de agrupamento hierárquico para discriminar os reflorestamentos com 3 (REF3), 5 (REF5) e 7 anos (REF7) e uma área de mata nativa (MATA) na Reserva Ecológica de Guapiaçu (REGUA), Rio de Janeiro, Brasil.

Figure 3. Dendrogram of hierarchical cluster analysis to discriminate reforestations of 3 (REF3), 5 (REF5), and 7 years old (REF7), and in a native forest area (MATA) in the Guapiaçu Ecological Reserve (REGUA), state of Rio de Janeiro, Brazil.

\section{DISCUSSÃO}

A hipótese testada de que o estoque de carbono na biomassa aérea total aumenta ao longo do gradiente crescente de idade dos reflorestamentos foi corroborada. A presença de gradiente no estoque de carbono florestal em função do tempo se torna relevante no contexto de projetos de reflorestamento para fins de conservação ambiental. No âmbito do Mecanismo de Desenvolvimento Limpo (MDL), bem como dos projetos de Redução de Emissões do Desmatamento e da Degradação Florestal (REDD), estudos para estimar esses estoques são necessários já que a conservação de áreas florestais é uma forma eficiente de garantir, a longo prazo, a estimativa do crédito de carbono gerado.

Corte et al. (2012) afirmam que são ainda escassas as informações acerca da dinâmica das florestas nativas em diferentes ecorregiões com enfoque na geração de estimativas e dados confiáveis de estoque de carbono na biomassa florestal. Dessa forma, projetos de carbono poderiam ser estabelecidos em grandes áreas de florestas naturais somadas às áreas de plantio para recuperação de áreas degradadas no bioma Mata Atlântica, tanto a nível ambiental quanto econômico.

Ao longo da sucessão ecológica, ocorre incremento de biomassa em florestas tropicais em função do aumento da abundância de espécies exclusivas de estágios sucessionais mais avançados, que apresentam tronco com maior volume (CHAZDON, 2012). No entanto, de uma maneira geral, este acúmulo de biomassa em florestas tropicais se processa de maneira mais acelerada até os 20 primeiros anos, com posterior desaceleração em função da estabilização da produtividade primária ou do aumento da respiração (BROWN; LUGO, 1990). Portanto, a desaceleração da produção de serapilheira com o aumento da idade de florestas tropicais (DICKOW et al., 2012) pode ser responsável pela tendência à diminuição da biomassa da camada de serapilheira, conforme verificado na comparação entre REF7 e MATA.

A semelhança entre os plantios de restauração com relação ao estoque de carbono na serapilheira pode estar relacionada com a abundância de espécies pioneiras empregadas nos plantios, que foi maior nas duas primeiras áreas (54\% e 59\%, respectivamente) em relação a REF3 (48\%). Em áreas onde predominam espécies pioneiras, pode ser verificada maior produção de serapilheira devido ao crescimento acelerado de tais espécies, o que contribui para o maior estoque de serapilheira (LAURANCE; VASCONCELOS, 2009). Isso corrobora a importância da escolha de espécies pioneiras em plantios de restauração florestal, que irão produzir maior biomassa em um curto período de tempo.

FLORESTA, Curitiba, PR, v. 48, n. 2, p. 183-194, abr/jun. 2018.

Azevedo. A. D. et.al.

ISSN eletrônico 1982-4688

DOI: $10.5380 /$ rf.v48 i 2.54447 
O expressivo emprego de espécies da família das Fabaceae e do grupo sucessional das pioneiras nos plantios de restauração foi responsável por sua contribuição na biomassa viva nas referidas áreas. Muitas espécies florestais que pertencem a essa família são capazes de se associar a bactérias fixadoras de nitrogênio atmosférico. Com isso, aportam matéria orgânica responsável pelo enriquecimento nutricional do solo superficial (camada de $0-20 \mathrm{~cm}$ ), que se reflete no favorecimento da regeneração natural de uma comunidade de plantas nativas com elevada diversidade no sub-bosque do plantio (CITADINI-ZANETTE et al., 2017). Na MATA, a família mais representativa foi Meliaceae (28\%), seguida de Fabaceae (14\%), sendo que as pioneiras também predominaram nessa área (39\%) (Tabela 2).

A biomassa total acima do solo e, consequentemente, o estoque de carbono na mata nativa foram aproximadamente quatro vezes maiores do que os observados nos plantios de reflorestamento. Considera-se esse resultado como consequência dos maiores valores de área basal na mata nativa, conforme pode ser observado para as dez espécies arbóreas que apresentaram as maiores contribuições percentuais na produção de biomassa viva acima do solo. A acumulação de biomassa se apresenta proporcional à área basal das florestas, a qual aumenta conforme sua idade (CHAZDON, 2012). Apesar disso, o estoque de serapilheira foi maior nos plantios mais velhos (REF5 e REF7) em comparação com a MATA.

O maior crescimento relativo das espécies pioneiras, comparado com o das espécies não-pioneiras, devese ao fato de que as primeiras colonizam áreas com elevada disponibilidade de radiação luminosa, recurso indispensável para o incremento de biomassa vegetal. Além disso, o efeito facilitador da regeneração natural na Mata Atlântica, observado em reflorestamentos onde se empregam exclusivamente espécies arbóreas pioneiras, pode ser comparado àquele verificado em plantios onde se empregam mudas de espécies de diferentes grupos ecológicos (KLIPPEL et al., 2015). Dessa maneira, deve-se priorizar o emprego de espécies pioneiras em reflorestamentos.

A comparação entre os resultados de biomassa aérea viva do presente trabalho e os dados de outros trabalhos conduzidos em diferentes áreas de Floresta Ombrófila Densa, que também empregaram o método nãodestrutivo (Tabela 3), deve ser realizada com cautela, pois alguns trabalhos não informaram expressamente se houve a inclusão de palmeiras no inventário. Além disso, existe ampla variação entre os inventários com relação ao critério de inclusão dos indivíduos arbóreos (valor mínimo de DAP).

Tabela 3. Valores médios de diâmetro à altura do peito (DAP) e de estoque total de carbono na biomassa viva aérea (CBA) e na camada de serapilheira (CCS) $\left(\mathrm{Mg} \mathrm{ha}^{-1}\right)$ em áreas de Floresta Ombrófila Densa.

Table 3. Mean values for diameter at breast height (DAP) and total carbon stock in aboveground live biomass (CBA) and in litter layer standing stock (CCS) (Mg ha-1) at areas of Dense Ombrophylous Forest

\begin{tabular}{|c|c|c|c|c|}
\hline Local & $\begin{array}{l}\text { DAP } \\
(\mathbf{c m})\end{array}$ & CBA & CCS & Referência \\
\hline Montana e Submontana, Cachoeiras de Macacu, RJ & $\geq 4,0$ & 136,68 & 2,26 & Este estudo* \\
\hline Submontana, Guaraqueçaba, PR & $<5,0$ & 109,30 & na & Tiepolo et al. $(2002) *$ \\
\hline Terras Baixas, Guaraqueçaba, PR & $<5,0$ & 83,69 & 1,70 & \\
\hline $\begin{array}{l}\text { Montana ( } 900 \text { m de altitude), Santa Maria } \\
\text { Madalena, RJ }\end{array}$ & $>10,0$ & 65,95 & 3,51 & Cunha et al. (2009)** \\
\hline $\begin{array}{l}\text { Montana ( } 600 \mathrm{~m} \text { de altitude), Santa Maria } \\
\text { Madalena, RJ }\end{array}$ & $>10,0$ & 68,43 & 3,68 & \\
\hline Submontana, Ubatuba, SP & $\geq 4,8$ & $61,93 * * *$ & na & \\
\hline Terras Baixas, Ubatuba, SP & $\geq 4,8$ & $51,20 * * *$ & na & \\
\hline Montana, Parque Estadual da Serra do Mar, SP & $>10,0$ & 122,38 & 2,64 & Vieira et al. $(2011)^{*}$ \\
\hline Submontana, Parque Estadual da Serra do Mar, SP & $>10,0$ & 111,21 & 3,54 & \\
\hline Terras Baixas, Parque Estadual da Serra do Mar, SP & $>10,0$ & 93,10 & 4,00 & \\
\hline "Vale (valley forest)" & $\geq 4,8$ & 144,25 & na & \\
\hline Montana, Parque Estadual da Serra do Mar, SP & $\geq 4,8$ & $82,40 * * *$ & na & $\begin{array}{l}\text { Marchiori et al. } \\
(2016)^{*}\end{array}$ \\
\hline
\end{tabular}

*incluindo palmeiras; **não informou se as palmeiras foram incluídas; ***valor calculado multiplicando-se a biomassa por 0,5 já que o estoque de carbono na biomassa não foi informado pelos autores; na: não avaliado.

Houve variação em relação às equações alométricas empregadas por Tiepolo et al. (2002), Cunha et al. (2009), Vieira et al. (2011) e Marchiori et al. (2016). No entanto, considerando os dados obtidos por trabalhos conduzidos sob condições mais semelhantes às do presente estudo (valor do critério de inclusão no inventário, DAP mais próximo do apresentado no presente estudo, e mesma tipologia florestal, Floresta Ombrófila 
Densa), o estoque total de carbono na biomassa aérea viva deste estudo foi praticamente o dobro do que foi verificado por Alves et al. (2010) e Marchiori et al. (2016).

Considerando o gradiente altitudinal, alguns trabalhos demonstraram que a biomassa aérea arbórea aumentou com a altitude em áreas de Floresta Ombrófila Densa (TIEPOLO et al., 2002; ALVES et al., 2010; VIEIRA et al., 2011). Consequentemente, estimativas apontam que o estoque de carbono nesse compartimento aumentou aproximadamente $50 \mathrm{Mg} \mathrm{ha}{ }^{-1}$ ao se compararem as altitudes de 100 e $1000 \mathrm{~m}$ (VILLELA et al., 2012). Tal resultado parece ser influenciado pela ocorrência de elevada precipitação pluviométrica, cuja distribuição ao longo do ano é mais homogênea, o que favorece o crescimento florestal (ROSENFIELD; SOUZA, 2014).

No entanto, resultados contrastantes podem ser obtidos ao se considerarem diferentes classe de DAP. Embora Scaranello et al. (2012) tenham verificado o incremento da biomassa viva aérea com o aumento da altitude para árvores com DAP > $30 \mathrm{~cm}$, o aumento da biomassa com o aumento da altitude não foi observado para árvores com DAP > $100 \mathrm{~cm}$. Sob elevadas altitudes, principalmente a partir de $1500 \mathrm{~m}$ acima do nível do mar (VILLELA et al., 2012), o menor crescimento de Floresta Atlântica ocorre em função da diminuição da incidência da radiação solar pela formação de nuvens espessas e densa neblina, o que ocasiona menores valores de temperatura do ar (SOUSA NETO et al., 2011) e menor disponibilidade de nitrogênio e fósforo no solo para as plantas.

A partir da estimativa total de biomassa viva acima do solo na mata nativa, aproximadamente $98 \%$ dos resultados foram relativos a indivíduos arbóreos $\left(266,76 \mathrm{Mg} \mathrm{ha}^{-1}\right)$, enquanto o restante estava relacionado a palmeiras $\left(6,59 \mathrm{Mg} \mathrm{ha}^{-1}\right)$. A contribuição percentual de palmeiras observada no presente trabalho foi próxima à verificada em outros trabalhos conduzidos em Floresta Ombrófila Densa (ALVES et al., 2010), que ficou em torno de 4 a 6\%. Ressalta-se que a elevada abundância de Euterpe edulis, resultado também verificado por Marchiori et al. (2016), é um indicativo do bom estado de preservação da mata nativa, visto que essa espécie está ameaçada de extinção devido à exploração predatória de palmito. O mesmo pode ser dito com relação a Astrocaryum aculeatissimum, cuja presença se encontra alarmantemente diminuída em fragmentos pequenos de Mata Atlântica devido a sua extração e baixo recrutamento, ocasionado pela diminuição na abundância de cotias (Dasyprocta agouti), pequenos roedores responsáveis pela sua dispersão natural.

Neste estudo, o estoque total de carbono na camada de serapilheira na mata nativa foi considerado baixo quando comparado ao de outras áreas de Floresta Ombrófila Densa (Tabela 3). A produção de serapilheira, por ser uma função da produtividade primária líquida, foi proporcional à biomassa florestal (MALHI et al., 2011). Portanto, esse resultado foi, provavelmente, o reflexo da inclusão de indivíduos arbóreos com DAP relativamente menores na nossa amostragem, em relação aos demais estudos.

O aumento da contribuição do material reprodutivo na camada de serapilheira com o avançar da idade está relacionado, provavelmente, à maior quantidade de frutos carnosos produzidos por espécies não-pioneiras e dispersados por animais, que geralmente são maiores e mais pesados do que os frutos típicos de espécies pioneiras com dispersão anemocórica. Esse fato também pode ser atribuído ao tempo de frutificação das espécies, que ocorre com o decorrer da idade dos plantios.

A diminuição progressiva da contribuição da braquiária na camada de serapilheira com o aumento da idade dos reflorestamentos demonstrou que o controle anual da matocompetição com capina manual (complementada com duas capinas químicas no primeiro ano e que ocorreu por até dois anos após a instalação dos plantios) foi efetivo. Em plantios de reflorestamento, o controle de Brachiaria decumbens, que compete diretamente com as árvores por água, nutrientes e luz, permitiu o incremento de biomassa aérea arbórea em plantios de reflorestamento de áreas de Mata Atlântica no município de Linhares, estado do Espírito Santo (KLIPPEL et al., 2015).

Utilizando o método destrutivo, Britez et al. (2006) verificaram valores na ordem de 187,34 $\mathrm{Mg} \mathrm{C}^{-1}$ para o carbono estocado na biomassa acumulada das árvores que se encontram nas faixas topográficas submontanas (20-600 m de altitude) da Floresta Ombrófila Densa do Paraná. Nessas mesmas áreas, Tiepolo et al. (2002) observaram que a tipologia submontana foi a que conteve maior estoque de carbono na biomassa acima do solo $\left(135,89 \mathrm{Mg} \mathrm{C} \mathrm{ha}^{-1}\right)$, sendo tal valor condizente com os resultados obtidos para a mesma fitofisionimia florestal neste estudo.

Os resultados da análise de agrupamento hierárquico corroboraram o padrão de que os valores de biomassa aérea viva e de serapilheira, bem como o estoque de carbono nos respectivos compartimentos, aumentaram progressivamente nos reflorestamentos ao longo do tempo. Apesar disso, a dissimilaridade entre os reflorestamentos e a MATA ainda é muito grande, de acordo com a baixa distância de similaridade ou ligação observada entre eles (aproximadamente 0,30).

Em ambiente de Floresta Ombrófila Densa Submontana no estado do Rio de Janeiro, a produtividade de biomassa viva aérea em um fragmento secundário formado por regeneração natural (60 anos após completo desflorestamento nos limites da REGUA) atingiu níveis parecidos (297 $\mathrm{Mg} \mathrm{ha}^{-1}$ ) aos verificados em mata preservada (313 $\mathrm{Mg} \mathrm{ha}^{-1}$ ), presente em uma área de conservação próxima. Dessa maneira, acredita-se que, caso não haja perturbações nos reflorestamentos estudados, a biomassa aérea viva e, consequentemente, a biomassa da

FLORESTA, Curitiba, PR, v. 48, n. 2, p. 183-194, abr/jun. 2018.

Azevedo. A. D. et.al.

ISSN eletrônico 1982-4688

DOI: $10.5380 /$ rf.v48 i 2.54447 
camada de serapilheira poderão se aproximar cada vez mais da mata nativa com o aumento de suas idade. Portanto, a implantação de plantios de restauração de áreas de Mata Atlâtica tem importante contribuição para o estoque de carbono, pois potencializa o carbono estocado em áreas de mata nativa e atua na mitigação dos efeitos causados pelas mudanças climáticas globais.

\section{CONCLUSÕES}

- A biomassa aérea viva e a biomassa da camada de serapilheira, bem como o estoque de carbono nesses compartimentos, aumentaram nas áreas restauradas conforme o incremento em idade. Portanto, tendem a aumentar de acordo com o desenvolvimento dos reflorestamentos, mostrando a importância dessas formações florestais no sequestro de carbono atmosférico.

- Houve elevada dissimilaridade entre as áreas restauradas e a área de floresta nativa preservada, que apresentou maiores valores de biomassa aérea e carbono estocado. Foram obtidos 39,88; 45,78; 71,24; 273,35 $\mathrm{Mg} \mathrm{ha}^{-1} \mathrm{de}$ biomassa total e 21,$85 ; 25,78 ; 38,29$ e $138,94 \mathrm{Mg} \mathrm{ha}^{-1}$ de carbono total estocado para REF3, REF5, REF7 e MATA, respectivamente.

- Ao constatar-se a ocorrência do gradiente de carbono em função da idade dos plantios de recomposição florestal, evidencia-se a importância do estudo para os efeitos do sequestro e fixação de carbono nas florestas naturais e plantadas com fins de restauração no bioma Mata Atlântica, como a mitigação dos gases do efeito estufa.

- Estudos de quantificação de biomassa e estimativas de estoques de carbono nos compartimentos aéreos e na camada de serapilheira no solo das áreas reflorestadas podem ser usados como referência para elaboração de projetos de neutralização de carbono na esfera do Mecanismo de Desenvolvimento Limpo (MDL). Estudos relacionados à atividade de recuperação de áreas degradadas com o plantio de espécies florestais nativas podem ser usados no âmbito dos projetos de Redução de Emissões do Desmatamento e da Degradação Florestal (REDD).

- O método indireto não-destrutivo, empregado para a estimativa de biomassa acima do solo e estoque de carbono, mostrou-se efetivo para os ecossistemas florestais estudados.

\section{REFERÊNCIAS}

ALONSO, J. M.; LELES, P. S. S.; FERREIRA, L. N.; OLIVEIRA, N. S. A. Aporte de serapilheira em plantio de recomposição florestal em diferentes espaçamentos. Ciência Florestal, Santa Maria, v. 25, n. 1, p. 1 - 11, 2015.

BALBINOT, R.; TRAUTENMÜLLER, J. W.; CARON, B. O.; BORELLA, J.; JUNIOR, S. C.; BREUNIG, F. M. Vertical distribution of aboveground biomass in a seasonal deciduous forest. Revista Brasileira de Ciências Agrárias, Recife, v. 12, n. 3, p. 361 - 365, 2017.

BRITEZ, R. M.; BORGO, M.; TIEPOLO, G.; FERRETTI, A.; CALMON, M.; HIGA, R. Estoques e incremento de carbono em florestas e povoamentos de espécies arbóreas com ênfase na floresta atlântica do sul do Brasil. Colombo: Embrapa Florestas, 2006. 165p.

BROWN, S.; LUGO, A. Forest Tropical Secondary. Journal of Tropical Ecology, Cambridge, v. 6, n. 1, p. 1 32, 1990.

CHAZDON, R. Regeneração de florestas tropicais. Boletim do Museu Paraense Emílio Goeldi Ciências Naturais, Belém, v. 7, n. 3, p. 195 - 218, 2012.

CITADINI-ZANETTE, V.; NEGRELLE, R. R. B.; LEAL-FILHO, L. S.; REMOR, R.; ELIAS, G. A.; SANTOS, R. Mimosa scabrella Benth. (Fabaceae) enhances the restoration in coal mining areas in the Atlantic Rainforest. Cerne, Lavras, v. 23, n. 1, p. 103 - 114, 2017.

ClARK, D. A.; BROWN, S.; KICKLIGHTER, D. W.; CHAMBERS, J. Q.; THOMLINSON, J. R., NI, J. Measuring net primary production in forests: concepts and field methods. Ecological Applications, Washington, v. 11 , p. $356-370,2001$.

CORTE, A. P. D.; SANQUETTA, C. R.; KIRCHNER, F. F.; ROSOT, N. C. Os projetos de redução de emissões do desmatamento e da degradação florestal (REDD). Floresta, Curitiba, v. 42, n. 1, p. 177 - 188, 2012.

DALlAGNOL, F. S.; MOGNON, F.; SANQUETTA, C. R.; CORTE, A. P. D. Teores de carbono de cinco espécies florestais e seus compartimentos. Floresta e Ambiente, Seropédica, v. 18, n. 4, p. 410 - 416, 2011. 
DICKOW, K. M. C.; MARQUES, R.; PINTO, C. B.; HÖFER H. Produção de serapilheira em diferentes fases sucessionais de uma floresta subtropical secundária, em Antonina, PR. Cerne, Lavras, v. 18, n. 1, p. 75 - 86, 2012.

HOPKINS, F. M; TORN, M. S.; TRUMBORE, S. E. Warming accelerates decomposition of decades-old carbon in forest soils. Proceedings of the National Academy of Sciences of the United States of America, Washington, v. 109, n. 26, p. 1753 - 1761, 2012.

JOLY, C. A.; METZGER, J. P.; TABARELLI, M. Experiences from the Brazilian Atlantic Forest: ecological findings and conservation initiatives. New Phytologist, Lancaster, v. 204, n. 3, p. 459 - 473, 2014.

KLIPPEL, V. H.; PEZZOPANE, J. E. M.; SILVA, G. F.; CALDEIRA, M. V. W.; PIMENTA, L. R.; TOLEDO, J. V. Avaliação de métodos de restauração florestal de Mata de Tabuleiros-ES. Revista Árvore, Viçosa, v. 39, n. 1, p. $69-79,2015$.

LAURANCE, W. F.; VASCONCELOS, H. L. Conseqüências ecológicas da fragmentação florestal na Amazônia. Oecologia Brasiliensis, Rio de Janeiro, v. 13, n. 3, p. 434 - 451, 2009.

MALHI, Y.; DOUGHTY, C.; GALBRAITH, D. The allocation of ecosystem net primary productivity in tropical forests. Philosophical Transactions of the Royal Society B, London, v. 366, p. 3225 - 3245, 2011.

MARCHIORI, N. M.; ROCHA, H. R.; TAMASHIRO, J. Y.; AIDAR, M. P. M. Tree community composition and aboveground biomass in a secondary Atlantic Forest, Serra do Mar State Park, São Paulo, Brazil. Cerne, Lavras, v. 22 , n. 4 , p. $501-514.2016$.

PINHEIRO, H. S. K.; ANJOS, L. H. C.; CHAGAS, C. S. Mapeamento Digital de Solos por Redes Neurais Artificiais - Estudo de caso da bacia hidrográfica do rio Guapi-Macacu. 1. ed. Saarbrucken: Novas Edições Acadêmicas - NEA, 2014. v. 1. 175p.

REBOITA, M. S.; ROCHA, R. P.; DIAS, C. G.; YNOUE, R. Y. Climate Projections for South America: RegCM3 Driven by HadCM3 and ECHAM5. Advances in Meteorology, London, v, 2014, p. 1 - 17, 2014.

ROSENFIELD, M. F.; SOUZA, A. F. Forest biomass variation in Southernmost Brazil: the impact of Araucaria trees. Revista de Biología Tropical, San José, v. 62, n. 1, p. 359 - 372, 2014.

SCARANELlO, M. A. S.; ALVES, L. F.; VIEIRA, S. A.; CAMARGO, P. B.; JOLY, C. A.; MARTINELLI, L. A. Height-diameter relationships of tropical Atlantic moist forest trees in southeastern Brazil. Scientia Agricola, Piracicaba, v. 69, n. 1, p. 26 - 37, 2012.

SOUSA NETO, E.; CARMO, J. B.; KELLER, M.; MARTINS, S. C.; ALVES, L. F.; VIEIRA, S. A.; PICCOLO, M. C.; CAMARGO, P.; COUTO, H. T. Z.; JOLY, C. A.; MARTINELLI, L. A. Soil-atmosphere exchange of nitrous oxide, methane and carbon dioxide in a gradient of elevation in the coastal Brazilian Atlantic Forest. Biogeosciences, Göttingen, v. 8, p. $733-742,2011$.

TIEPOLO, G.; CALMON, M.; FERRETTI, A. R. Measuring and Monitoring Carbon Stocks at the Guaraqueçaba Climate Action Project, Paraná, Brazil. In: International Symposium on Forest Carbon Sequestration and Monitoring. Extension Series Taiwan Forestry Research Institute, n. 153, p. 98 - 115, 2002.

VIEIRA, S. A.; ALVES, L. F.; DUARTE-NETO, P. J.; MARTINS, S. C.; VEIGA, L. G.; SCARANELLO, M. A.; PICOLlO, M. C.; CAMARGO, P. B.; CARMO, J. B.; SOUSA NETO, E.; SANTOS, F. A. M.; JOLY, C. A.; MARTINELLI, L. A. Stocks of carbon and nitrogen and partitioning between above- and belowground pools in the Brazilian coastal Atlantic Forest elevation range. Ecology and Evolution, New Jersey, v. 1, n. 3, p. 421 - 434 , 2011.

VILLELA, D. M.; de MATTOS, E. A.; PINTO, A. S.; VIEIRA, A. S.; MARTINELLI, L. A. Carbon and nitrogen stock and fluxes in coastal Atlantic Forest of southeast Brazil: potential impacts of climate change on biogeochemical functioning. Brazilian Journal of Biology, São Carlos, v. 72, n. 3, p. 633 - 642, 2012.

WATZLAWICK, L. F.; MARTINS, P. J.; RODRIGUES, A. L.; EBLING, A. A.; BALBINOT, R.; LUSTOSA, S. B. C. Teores de carbono em espécies da floresta ombrófila mista e efeito do grupo ecológico. Cerne, Lavras, $\mathrm{V}$ .20 , n. 4, p. $613-620,2014$.

FLORESTA, Curitiba, PR, v. 48, n. 2, p. 183-194, abr/jun. 2018.

Azevedo. A. D. et.al.

ISSN eletrônico 1982-4688

DOI: $10.5380 /$ rf.v48 i 2.54447 
FLORESTA, Curitiba, PR, v. 48, n. 2, p. 183-194, abr/jun.2108. Azevedo. A. D. et.al. 